Prepared in cooperation with the Bureau of Land Management

\title{
Multiscale Sagebrush Rangeland Habitat Modeling in Southwest Wyoming
}

\section{Open-Fle Report 2008-1027}

U.S. Department of the Interior U.S. Geological Survey 
Cover photograph: Basin Big Sagebrush, North Bridger Creek, southwest Wyoming. Photograph by Collin Homer. 


\section{Multiscale Sagebrush Rangeland Habitat Modeling in Southwest Wyoming}

By Collin G. Homer, Cameron L. Aldridge, Debra K. Meyer, Michael J. Coan, and Zachary H. Bowen

Prepared in cooperation with the Bureau of Land Management

Open-File Report 2008-1027 


\title{
U.S. Department of the Interior DIRK KEMPTHORNE, Secretary
}

\section{U.S. Geological Survey \\ Mark D. Myers, Director}

\section{U.S. Geological Survey, Reston, Virginia: 2009}

\author{
This and other USGS information products are available at $h t t p: / / s t o r e . u s g s . g o v /$ \\ U.S. Geological Survey \\ Box 25286, Denver Federal Center \\ Denver, CO 80225 \\ To learn about the USGS and its information products visit http://www.usgs.gov/ \\ 1-888-ASK-USGS
}

\begin{abstract}
Any use of trade, product, or firm names is for descriptive purposes only and does not imply endorsement by the U.S. Government.

Although this report is in the public domain, permission must be secured from the individual copyright owners to reproduce any copyrighted materials contained within this report.
\end{abstract}

Suggested citation:

Homer, C.G., Aldridge, C.L., Meyer, D.K., Coan, M.J., and Bowen, Z.H., 2009, Multiscale sagebrush rangeland habitat modeling in southwest Wyoming: U.S. Geological Survey Open-File Report 2008-1027, 14 p. 


\section{Contents}

Abstract
Introduction.
$\quad$ Surpose and Scope

\section{Figures}

1. Map showing location and spatial extent of the three study areas for mapping sagebrush habitats in 2006

2. Field plot design for sampling rangeland components using 14 quadrats within each sample polygon.

3-4. Maps showing:

3. Location of accuracy assessment plots in microstudy area by three predefined shrub-canopy cover strata.....

4. Location of 10 accuracy assessment focus areas across the

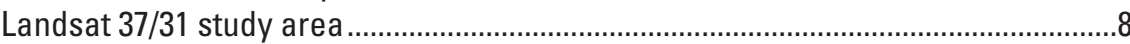

5-6. Imagery showing:

5. Example of percent bare ground predictions in QuickBird site 3 at three spatial scales

6. Examples of predictions for four primary components from QuickBird imagery in QuickBird site 3

7-8. Graphs showing:

7. Predicted versus measured sagebrush canopy cover (Artemisia spp.) from Landsat imagery for the Landsat 37/31 study area

8. Landsat sagebrush prediction accuracy, by QuickBird training site combinations

9. Map showing the location of 2006 and 2007 QuickBird samples over the 2001 National Land Cover Database.

\section{Tables}

1. Input layer number and type used to model components ...............................................5

2. Relation of QuickBird acquisitions to field sampling dates ...............................................

3. Accuracy assessment of all variable predictions for each study site and sensor .........10 


\section{Conversion Factors}

\begin{tabular}{lcl}
\hline Multiply & By & To obtain \\
\hline centimeter $(\mathrm{cm})$ & Length & \\
meter $(\mathrm{m})$ & 0.3937 & inch (in.) \\
square meter $\left(\mathrm{m}^{2}\right)$ & 3.281 & foot (ft) \\
kilometer $(\mathrm{km})$ & 10.76 & square foot $\left(\mathrm{ft}^{2}\right)$ \\
& 0.6214 & mile (mi) \\
\hline hectare (ha) & Area & \\
square kilometer $\left(\mathrm{km}^{2}\right)$ & 2.471 & acre \\
hectare (ha) & 247.1 & acre \\
square kilometer $\left(\mathrm{km}^{2}\right)$ & 0.003861 & square mile $\left(\mathrm{mi}^{2}\right)$ \\
\hline
\end{tabular}




\title{
Multiscale Sagebrush Rangeland Habitat Modeling in Southwest Wyoming
}

\author{
By Collin G. Homer', Cameron L. Aldridge ${ }^{2}$, Debra K. Meyer ${ }^{3}$, Michael J. Coan ${ }^{3}$, and Zachary H. Bowen ${ }^{1}$
}

\section{Abstract}

Sagebrush-steppe ecosystems in North America have experienced dramatic elimination and degradation since European settlement. As a result, sagebrush-steppe dependent species have experienced drastic range contractions and population declines. Coordinated ecosystem-wide research, integrated with monitoring and management activities, would improve the ability to maintain existing sagebrush habitats. However, current data only identify resource availability locally, with rigorous spatial tools and models that accurately model and map sagebrush habitats over large areas still unavailable. Here we report on an effort to produce a rigorous large-area sagebrush-habitat classification and inventory with statistically validated products and estimates of precision in the State of Wyoming. This research employs a combination of significant new tools, including (1) modeling sagebrush rangeland as a series of independent continuous field components that can be combined and customized by any user at multiple spatial scales; (2) collecting ground-measured plot data on 2.4-meter imagery in the same season the satellite imagery is acquired; (3) effective modeling of ground-measured data on 2.4-meter imagery to maximize subsequent extrapolation; (4) acquiring multiple seasons (spring, summer, and fall) of an additional two spatial scales of imagery (30 meter and 56 meter) for optimal large-area modeling; (5) using regression tree classification technology that optimizes data mining of multiple image dates, ratios, and bands with ancillary data to extrapolate ground training data to coarser resolution sensors; and (6) employing rigorous accuracy assessment of model predictions to enable users to understand the inherent uncertainties. First-phase results modeled eight rangeland components (four primary targets and four secondary targets) as continuous field predictions. The primary targets included percent bare ground, percent herbaceousness, percent shrub, and percent litter. The four secondary targets included percent sagebrush (Artemisia spp.), percent big sagebrush (Artemisia

\footnotetext{
${ }^{1}$ U.S. Geological Survey.

${ }^{2}$ Natural Resource Ecology Laboratory, Colorado State University.

${ }^{3}$ Science Applications International Corporation (SAIC), contractor to the U.S. Geological Survey.
}

tridentata), percent Wyoming sagebrush (Artemisia tridentata wyomingensis), and sagebrush height (centimeters). Results were validated by an independent accuracy assessment with root mean square error (RMSE) values ranging from 6.38 percent for bare ground to 2.99 percent for sagebrush at the QuickBird scale and RMSE values ranging from 12.07 percent for bare ground to 6.34 percent for sagebrush at the full Landsat scale. Subsequent project phases are now in progress, with plans to deliver products that improve accuracies of existing components, model new components, complete models over larger areas, track changes over time (from 1988 to 2007), and ultimately model wildlife population trends against these changes. We believe these results offer significant improvement in sagebrush rangeland quantification at multiple scales and offer users products that have been rigorously validated.

\section{Introduction}

Historically, sagebrush-steppe ecosystems in North America have experienced dramatic elimination and degradation since European settlement, with remaining sagebrush habitats still undergoing further fragmentation and degradation (Connelly and others, 2004; Schroeder and others, 2004). As a result, sagebrush-steppe dependent species have experienced drastic range contractions and population declines, one notable example being sage-grouse (Centrocercus spp.). Sage-grouse populations have declined at a rate of approximately 2 percent per year since 1965 (Connelly and others, 2004), leaving populations threatened with extirpation in many of the habitats where they have historically persisted (Connelly and others, 2004; Aldridge and Boyce, 2007). Coordinated ecosystemwide research, integrated with monitoring and management activities would help maintain existing sagebrush habitats. However, current data generally only identify resource availability locally, with rigorous spatial tools and models that accurately model and map sagebrush habitats over large areas still unavailable (Connelly and others, 2004). Thus, managers are unable to monitor habitats over large areas, preventing deeper understanding of ecosystem science and implementation of landscape-scale management and conservation initiatives. 
Currently, remote sensing offers the best data source to both efficiently and effectively characterize sagebrush landscapes across a range of spatial and temporal scales. Semiarid shrub lands, such as sagebrush, offer challenging remote sensing environments, with spectral signatures (the repeated spectral pattern of land cover) often confounded by other factors. The primary factor is centered on the relatively sparse canopy cover, which means the spectral signature always has contributions from other elements and can be overwhelmed by contributions from bare ground, herbaceous vegetation, or topography. This confounding effect typically intensifies as spatial scale is increased and the opportunity for greater variations in sagebrush species, soil properties, topography, and associated vegetation are encountered. Hence, traditional remote sensing characterization in sagebrush landscapes has attempted only a category based approach using generalized land cover cover-types or classes for delineation. This more subjective approach can be quite effective across either local scales or for targeted applications, but quickly breaks down when the attempt is made to either broaden the use or repeat the process. Clearly, if remote sensing can offer operational solutions to the pressing need for sagebrush characterization and monitoring, a new paradigm is needed. In 2005, the U.S. Geological Survey, in cooperation with the Bureau of Land Management, began a study in Wyoming to explore new ways to characterize sagebrush habitats.

\section{Purpose and Scope}

The goal of this project is to develop a rigorous largearea sagebrush system inventory that provides statistically validated products with estimates of precision for quantifying the sagebrush ecosystem. We use a combination of significant new tools, imagery, and methods to characterize sagebrush systems, expanding beyond traditional category-based remote sensing methods still commonly used. This combination includes (1) modeling habitat as a series of independent continuous field components that can be synergistically customized by any user at multiple spatial scales; (2) collecting ground-measured plot data on 2.4-m imagery in the same season the satellite imagery is acquired; (3) effective modeling of ground-measured data on 2.4-m imagery to maximize subsequent extrapolation; (4) acquiring multiple seasons (spring, summer, and fall) of an additional two spatial scales of imagery (30 m and $56 \mathrm{~m}$ ) for optimal modeling; (5) using regression tree classification technology that optimizes data mining of multiple image dates, ratios, and bands with ancillary data to extrapolate ground training data to coarser resolution sensors (Homer and others, 2004); and (6) employing rigorous accuracy assessment of model predictions to enable users to understand the inherent uncertainties.

The first phase of this project is reported here, with southwest Wyoming as an initial priority area. This area has a relatively intact ecosystem but is targeted for new oil and gas development (subsequent project phases will encompass products for the entire State of Wyoming to provide a framework for future monitoring, management, and planning efforts on public rangelands across the State). Specific objectives include:

1. Develop and assess field sample protocols that support collection of training and testing (validation) data for optimal remote sensing predictions at multiple spatial scales.

2. Develop, assess, and compare the remote sensing methodologies necessary for predicting eight sagebrush system components (including percent bare ground, percent shrub, percent herbaceousness, percent litter, percent sagebrush, percent big sagebrush, percent wyomingensis sagebrush, and shrub height) across four $64-\mathrm{km}^{2}$ study sites with 2.4-m QuickBird imagery.

3. Develop, assess, and analyze new remote sensing methodologies for extrapolating 2.4-m QuickBird predictions of eight sagebrush system components across larger landscapes in southwest Wyoming on 30-m Landsat Thematic Mapper (TM) imagery and 56-m Indian Remote Sensing Advanced Wide Field Sensor (AWiFS) imagery.

Subsequent project phases are now in progress, with plans to deliver products that improve accuracies of existing components, model new components, complete models over larger areas, track changes over time (from 1988 to 2007), and ultimately model wildlife population trends against these changes. Specific products now under development include predictions for all eight rangeland components described here for the State of Wyoming based on 56-m AWiFS imagery, predictions of these components covering 75 percent of the State of Wyoming based on 30-m Landsat imagery, and selected areas of field sampling and classification from 2.4-m QuickBird imagery to densify training data and bolster component accuracy.

\section{Study Area}

The operational scale of our study is the State of Wyoming; however, this initial assessment and report are focused on three substudy areas within the southwest corner of Wyoming. We report on prediction results across these three areas, beginning with one of four analyzed QuickBird (QB) scenes (QB site 3), a microstudy area surrounding QB site 3, and a full Landsat scene study area encompassing Landsat scene Path 37, Row 31 (fig. 1). The QB site 3 study unit covers Bureau of Land Management land in the Jonah oil and gas field and provided a typical range of expected sagebrush rangeland conditions. The microstudy area includes the greater area surrounding QB site 3 and offered a small test area to carefully explore the extrapolation potential of Landsat and AWiFS imagery to unsampled areas on the basis of optimal training data and file size. The full Landsat study area (hereafter called 37/31) provided an opportunity to test the accuracy of predictions scaled up from the QuickBird to the Landsat 


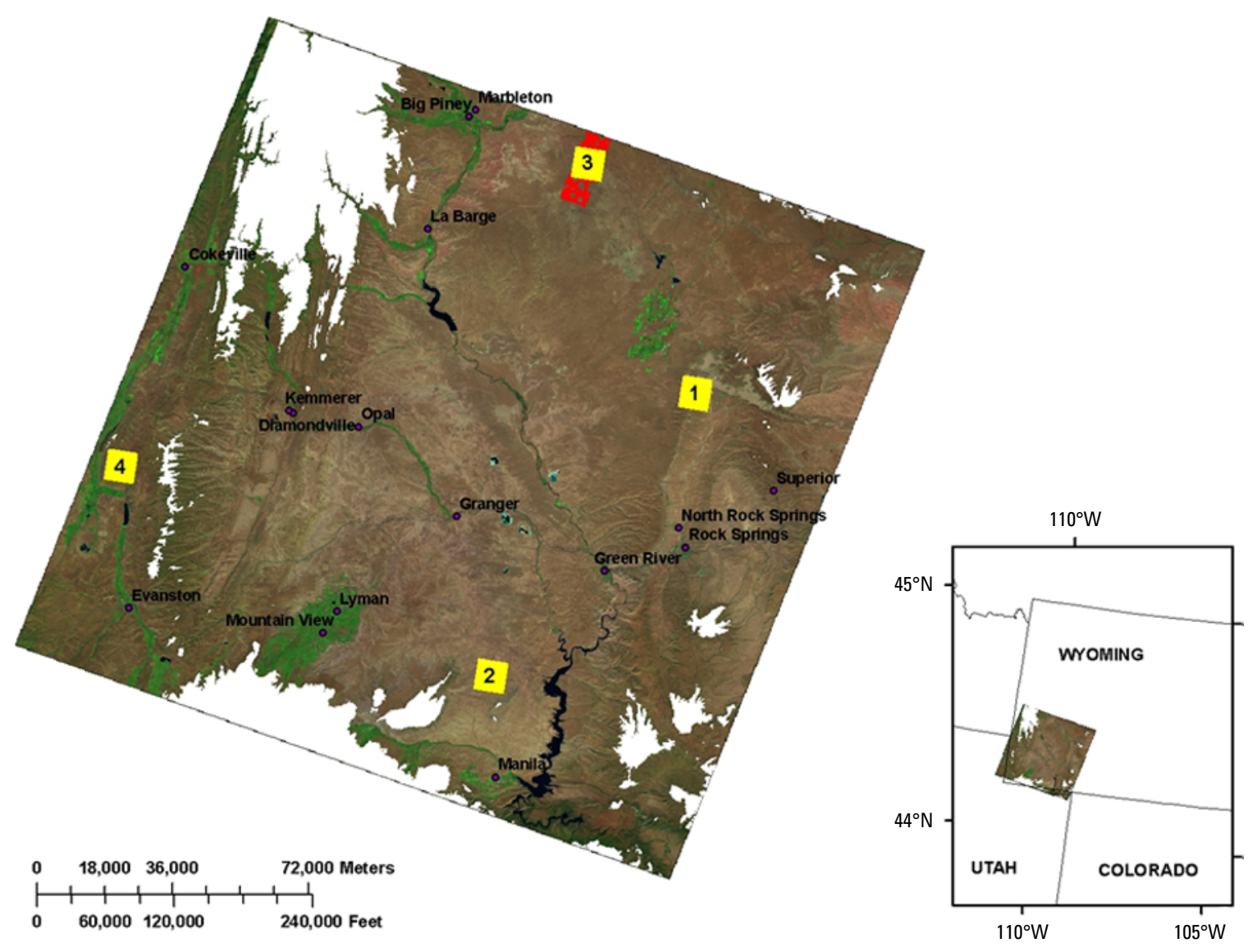

Figure 1. Location and spatial extent of the three study areas for mapping sagebrush habitats in 2006. Initial models were developed for QuickBird site 3 (yellow area, number 3 ) and were extrapolated to the microstudy area (red area) using Landsat/AWiFS imagery. Finally, all four QuickBird sites (yellow areas, numbers 1-4) were extrapolated on Landsat and AWiFS imagery to the entire Landsat scene study area represented in true color here (without the high elevation Wind River Range). 
scale under scenarios typical of future full-scale operational product to be created statewide.

\section{Methods}

We developed methods to combine 2.4-m QuickBird imagery, 30-m Landsat TM imagery, and 56-m AWiFS imagery coupled with rigorous ground sampling to develop continuous fractional vegetation predictions (for example, the percentage of the cell or pixel covered by the component) of eight sagebrush rangeland components. Components include four primary targets and four secondary targets. The four primary targets, which represent 100 percent of all cover, include percent bare ground, percent herbaceousness (grass and forb), percent shrub, and percent litter. The four secondary targets (subsets of primary targets) include percent sagebrush (Artemisia spp.), percent big sagebrush (A. tridentata), percent Wyoming sagebrush (A. t. wyomingensis), and mean sagebrush height (centimeters). Specific methodological descriptions are detailed in the following sections by project objective.

Field sampling protocols.-We used Definiens eCognition software to segment QuickBird imagery into uniform polygon patches to identify sites for potential field sampling. Each QuickBird image was also per-pixel classified into 30 unsupervised clusters by using an isodata algorithm in Leica Geosystems ERDAS Imagine software. Segmented polygons were then intersected with the 30 clusters to identify the majority cluster class in each polygon. Polygons representing the full range of spectral variability across the QuickBird image could then be selected. Typically, two sampling polygons from each of the 30 cluster classes were selected, for a minimum of 60 sample polygons per QuickBird footprint. Sample polygons were restricted in regard to the size of the patch ( $>0.5$ hectare), adjacency to roads (within $1 \mathrm{~km}$ ), land ownership access, and spatial distribution on the image. This selection process was designed to ensure that selected samples represented the spectral and ecological diversity within the QuickBird footprint. Plots were supplied to field crews for ground sampling as near to acquisition date as logistically possible and averaged $23 \pm 8.6$ (standard error) days for all four sampled QuickBird images.

Once polygons were selected within a QuickBird scene, we sampled vegetation characteristics at seven $1-\mathrm{m}^{2}$ quadrats along each of two 30-m transects, for 14 quadrats in total (fig. 2). The first transect was randomly placed $10 \mathrm{~m}$ from the polygon centroid and extended out in a randomly chosen direction from the centroid. Individual quadrats were placed every $5 \mathrm{~m}$ along the transect, beginning from the starting point. The second transect started $10 \mathrm{~m}$ from the polygon centroid but was oriented in the opposite direction from the first transect, extending parallel in the opposite direction from the first transect (fig. 2). For all 14 quadrats, we estimated cover from an overhead perspective (satellite), and the total cover of all vegetation types could not sum beyond 100 percent. Shrubs and trees were classified to the species level; with sagebrush cover identified at the subspecie level. All other components within the quadrat were combined into broad categories of herbaceous vegetation, litter, and bare ground. Cover measurements for shrubs were based only on portions of the canopy with live green vegetation. Cover measurements for herbaceous vegetation consisted of all grasses (live and residual standing) and forbs (including plants like selaginella, phlox, and cacti). Litter was estimated as the combined cover of dead standing woody vegetation (including exposed shrub stems) and all detached plant and animal organic matter. Bare ground included any exposed soil or rocks. All cover was estimated in 5-percent increments. We estimated the height of each shrub or tree species by measuring the droop height of the tallest green vegetation (excluding seed stalks) for one representative plant within each quadrat. We also recorded the presence of exotic grass species in each quadrat to allow subsequent estimation of abundance by polygon.

For application to remotely sensed data, we calculated the mean value for each of the variables of interest (see eight component variables listed previously) across all fourteen 1-m quadrats within a polygon. We assigned these values to all pixels occurring within the sampled area, defined as a polygon connecting the start and end of both transects.

QuickBird imagery predictions.-We classified the proportion of each of eight components occurring within all four QuickBird footprints on a per-pixel basis independently by using commercial regression tree (RT) software called Cubist (Quinlan, 1993), which identifies empirical relations between each component and the QuickBird data. Typically, all four 2.4-m spectral bands (bands 1-4) were used directly; an additional three bands of ratio indices were derived for capturing Green Normalized Difference Vegetation Index (NDVI; Band 4 - Band 2)/(Band $4+$ Band 2), Moisture Index (Band $4-$ Band 1)/(Band $4+$ Band 1), and Specific Leaf Area Vegetation Index (Band 4)/(Band $3+$ Band 2 ) for a total of seven input bands. We developed training inputs for each

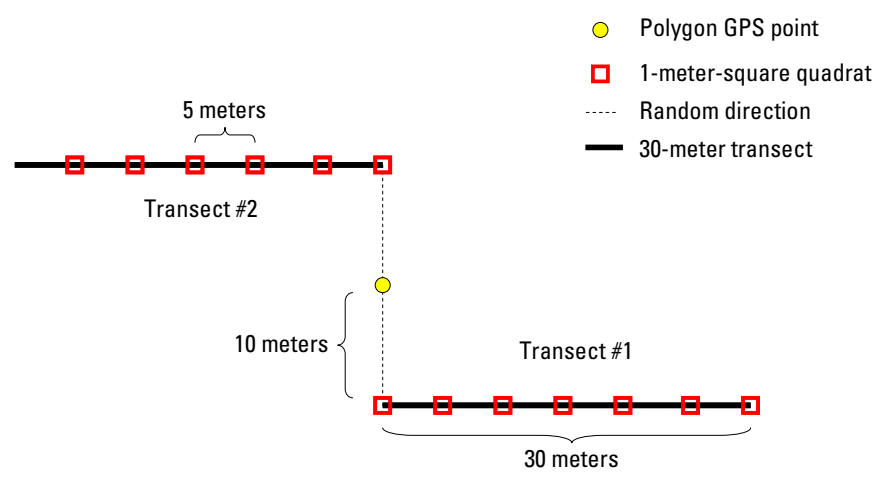

Figure 2. Field plot design for sampling rangeland components using 14 quadrats within each sample polygon. The polygon global positioning system (GPS) point (in yellow) represents the centroid of the polygon. 
component by using the average value for each sampled plot within each QuickBird footprint (typically 60 sample plots). Predictions quantifying the spatial distribution and per-pixel proportion of seven components as a continuous variable from 0 to 100 percent and shrub height $(\mathrm{cm})$ were then produced for all pixels in each QuickBird image. We initially assessed model fit by using a Pearson's correlation to compare sample training data with model predictions. We also assessed model robustness by summing the four independently modeled primary cover components (percent bare ground, shrub, herbaceousness, and litter) for every pixel across the whole scene. Because these four components added together should sum to 100 percent, the amount of reported deviation provided is an indication of primary model robustness. We also report the accuracy of predicted models versus observed measurements by using two common regression statistics: the coefficient of determination $\left(\mathrm{R}^{2}\right)$ and the root mean square error (RMSE). $\mathrm{R}^{2}$ is a common statistic, which represents a relative measure of model fit. RMSE represents an absolute measure of model fit and is in the same units as the model variable. It is the best statistic for the typical user to understand the predictive precision of our models.

Landsat and AWiFS imagery predictions.-We classified all eight rangeland components independently for both Landsat and AWiFS imagery at two spatial scales: the microstudy area, designed to facilitate rapid model iterations to fine-tune procedures under ideal extrapolation scenarios, and the full Landsat 37/31 study area, designed to test procedures under operational scenarios. We used each component prediction from the four QuickBird footprints (objective 2 ) and resampled them from 2.4-m cells to 30-m cells for Landsat imagery and to 56-m cells for AWiFS imagery to provide training data for the model predictions. The training data were then further refined by using a filtering model to eliminate outlier pixels. Only those pixels with prediction summations for the four primary components (percent bare ground, shrub, herbaceousness, and litter) that ranged from 90 percent to 110 percent were retained for training. To establish the optimal combination of covariates that best predicted our eight response variables, we conducted multiple trials with various combinations of input layers on the microstudy area. Potential input layer combinations were drawn from multiple image dates, ratios that targeted spectral content, ratio differences between these dates, and ancillary topographic data. The final combination of input layers used to derive model results consisted of 40 input layers for Landsat predictions and 34 input layers for AWiFS predictions (table 1). All Landsat images were corrected by using the Multi-Resolution Land Characteristics (MRLC) image protocol, which standardizes imagery to at-satellite reflectance before its use in the modeling (Homer and others, 2004). AWiFS images were not corrected to at-satellite reflectance, but they were used as standard digital numbers. These input layers represent the total data made available to Cubist for data mining to build model predictions for each component response variable.
Because RT models are sensitive to proportional weighting of data, we also conducted multiple trials to determine training data proportions required to provide the most accurate predictions. Analysis of each trial depended upon the cross-validated model fit and visual inspection to determine the best predictions. Ultimately, we divided data for each of the eight component response variables into three roughly equal bins, defined by thresholds derived from the mean and RMSE. Values less than the mean minus RMSE were grouped into a low bin, values greater than the mean plus RMSE were grouped into a high bin, and the remaining values were considered the middle bin. Because the resampling process inherently narrows the range of values and the RT models tend to concentrate on the most frequent values (in this case our medium predictions in the middle bin), this approach attempted to ensure that higher and lower component predictions would carry more equal weighting in model development and reduce overall bias. We created three iterations, or "bags," for each response variable, resulting in three unique predictions. We then calculated the mean of these three unique predictions as the final component response variable. Analysis based on the cross-validated results and visual interpretation revealed that this method typically resulted in a more consistent prediction than a single iteration model. We extrapolated predictions for all seven cover variables and the one height variable from 0 to 100 percent across all Landsat and AWiFS pixels in the microstudy and 37/31 areas.

We assessed model robustness, accuracy, and performance with the same metrics mentioned previously but used independent accuracy assessment plots collected in both the microstudy (32 plots) and Landsat 37/31 (71 plots) study areas during the same season as the training data. Sample locations for assessment plots were randomly generated in the microstudy area across three shrub-canopy cover strata, with approximately 10 plots in each area representing high, medium, and low total shrub canopies. Shrub-canopy strata were defined by using an existing draft shrub-canopy model from previous independent work (C. Homer, and R. McKinley, unpub. data, 2005). Potential sample areas were restricted by using the same general approaches as those used for collecting sample plot training data (fig. 3).

In the $37 / 31$ study area, accuracy assessment plot locations were identified on the basis of several criteria. First, we stratified an existing draft sagebrush canopy model into areas representing high, medium, and low total shrub canopies (C. Homer, and R. McKinley, unpub. data, 2005). Next, the 2001 National Land Cover Database (NLCD 2001; Homer and others, 2007) was used to mask out everything but shrub, barren, and grass habitats, which were the focus of our modeling efforts. These areas were further reduced to retain only those habitats within $500 \mathrm{~m}$ of a road and on public land. Within this available sample, ten 5-km sample circles were randomly generated and buffered $5 \mathrm{~km}$ to create 10 sample focus areas. Inside each sample focus area, two points in each of the three shrub strata (six total) were randomly located 
Table 1. Input layer number and type used to model components.

[AWiFS, Advanced Wide Field Sensor. Diffs refers to differencing two bands to produce a difference layer]

\begin{tabular}{|c|c|c|}
\hline Layer number & Landsat input bands & AWiFS input bands \\
\hline Layer 01 & May 14, 2006, Landsat 5, Band 1 & June 24, 2006, AWiFS, Band 1 \\
\hline Layer 02 & May 14, 2006, Landsat 5, Band 2 & June 24, 2006, AWiFS, Band 2 \\
\hline Layer 03 & May 14, 2006, Landsat 5, Band 3 & June 24, 2006, AWiFS, Band 3 \\
\hline Layer 04 & May 14, 2006, Landsat 5, Band 4 & June 24, 2006, AWiFS, Band 4 \\
\hline Layer 05 & May 14, 2006, Landsat 5, Band 5 & June 24, 2006, 3 Ratio Index Band 1 \\
\hline Layer 06 & May 14, 2006, Landsat 5, Band 6 & June 24, 2006, 3 Ratio Index Band 2 \\
\hline Layer 07 & May 14, 2006, 3 Ratio Index Band 1 & June 24, 2006, 3 Ratio Index Band 3 \\
\hline Layer 08 & May 14, 2006, 3 Ratio Index Band 2 & July 18, 2006, AWiFS, Band 1 \\
\hline Layer 09 & May 14, 2006, 3 Ratio Index Band 3 & July 18, 2006, AWiFS, Band 2 \\
\hline Layer 10 & July 17, 2006, Landsat 5, Band 1 & July 18, 2006, AWiFS, Band 3 \\
\hline Layer 11 & July 17, 2006, Landsat 5, Band 2 & July 18, 2006, AWiFS, Band 4 \\
\hline Layer 12 & July 17,2006 , Landsat 5, Band 3 & July 18, 2006, 3 Ratio Index Band 1 \\
\hline Layer 13 & July 17, 2006, Landsat 5, Band 4 & July 18, 2006, 3 Ratio Index Band 2 \\
\hline Layer 14 & July 17, 2006, Landsat 5, Band 5 & July 18, 2006, 3 Ratio Index Band 3 \\
\hline Layer 15 & July 17, 2006, Landsat 5, Band 6 & September 28, 2006, AWiFS, Band 1 \\
\hline Layer 16 & July 17, 2006, 3 Ratio Index Band 1 & September 28, 2006, AWiFS, Band 2 \\
\hline Layer 17 & July 17, 2006, 3 Ratio Index Band 2 & September 28, 2006, AWiFS, Band 3 \\
\hline Layer 18 & July 17, 2006, 3 Ratio Index Band 3 & September 28, 2006, AWiFS, Band 4 \\
\hline Layer 19 & September 3, 2006, Landsat 5, Band 1 & September 28, 2006, 3 Ratio Index Band 1 \\
\hline Layer 20 & September 3, 2006, Landsat 5, Band 2 & September 28, 2006, 3 Ratio Index Band 2 \\
\hline Layer 21 & September 3, 2006, Landsat 5, Band 3 & September 28, 2006, 3 Ratio Index Band 3 \\
\hline Layer 22 & September 3, 2006, Landsat 5, Band 4 & Aspect, 9 Direction \\
\hline Layer 23 & September 3, 2006, Landsat 5, Band 5 & Elevation, meters \\
\hline Layer 24 & September 3, 2006, Landsat 5, Band 6 & Slope Position Index \\
\hline Layer 25 & September 3, 2006, 3 Ratio Index Band 1 & Slope, degrees \\
\hline Layer 26 & September 3, 2006, 3 Ratio Index Band 2 & June 24, July 18, Ratio Diffs Index Band 1 \\
\hline Layer 27 & September 3, 2006, 3 Ratio Index Band 3 & June 24, July 18, Ratio Diffs Index Band 2 \\
\hline Layer 28 & Aspect, 9 Direction & June 24, July 18, Ratio Diffs Index Band 3 \\
\hline Layer 29 & Elevation, meters & June 24, September 28, Ratio Diffs Index Band 1 \\
\hline Layer 30 & Slope Position Index & June 24, September 28, Ratio Diffs Index Band 2 \\
\hline Layer 31 & Slope, degrees & June 24, September 28, Ratio Diffs Index Band 3 \\
\hline Layer 32 & May 14, July 17, Ratio Diffs Index Band 1 & July 18 , September 28, Ratio Diffs Index Band 1 \\
\hline Layer 33 & May 14, July 17, Ratio Diffs Index Band 2 & July 18 , September 28 , Ratio Diffs Index Band 2 \\
\hline Layer 34 & May 14, July 17, Ratio Diffs Index Band 3 & July 18 , September 28 , Ratio Diffs Index Band 3 \\
\hline Layer 35 & May 14, Sept 3, Ratio Diffs Index Band 1 & \\
\hline Layer 36 & May 14, Sept 3, Ratio Diffs Index Band 2 & \\
\hline Layer 37 & May 14, Sept 3, Ratio Diffs Index Band 3 & \\
\hline Layer 38 & July 17, Sept 3, Ratio Diffs Index Band 1 & \\
\hline Layer 39 & July 17, Sept 3, Ratio Diffs Index Band 2 & \\
\hline Layer 40 & July 17, Sept 3 Ratio Diffs Index Band 3 & \\
\hline
\end{tabular}




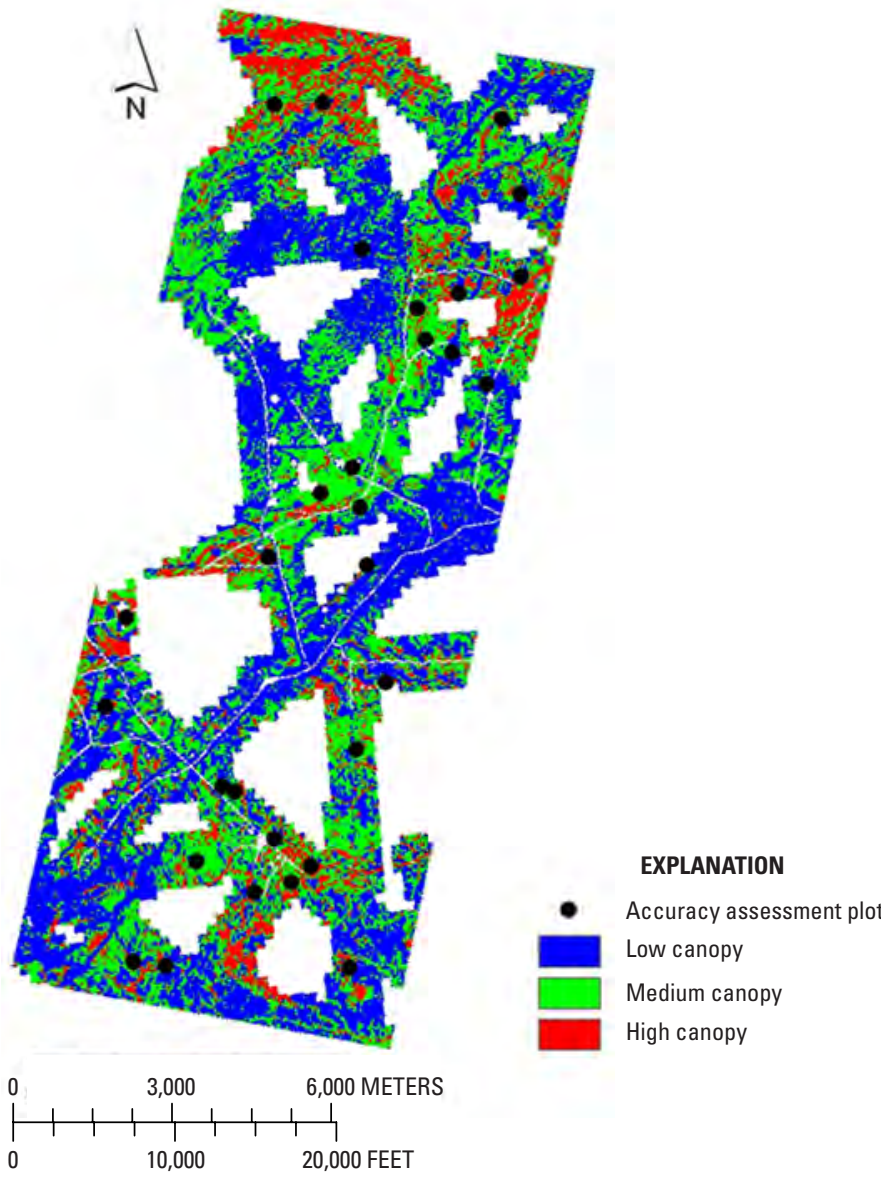

Figure 3. Location of accuracy assessment plots in microstudy area by three predefined shrub-canopy cover strata.

for sampling (fig. 4). The field protocols used for training plot collection were also used for plot sampling. Before final model assessment was completed, three classes from NLCD 2001 — shrub, herbaceous, and barren — were used to mask out non-rangeland areas in the final Landsat and AWiFS predictions.

\section{Results}

We generated spatial predictions for eight different rangeland components at three different spatial scales, including 2.4-m QuickBird, 30-m Landsat, and 56-m AWiFS (fig. 5). QuickBird results were generated across four $64-\mathrm{km}^{2}$ footprints, and Landsat and AWiFS results were generated across the microstudy and Landsat 37/31 study areas, respectively, in southwest Wyoming (fig. 1). Results by project objective are described in the following sections.

Field sampling results.-A total of 349 plots were sampled across the southwest Wyoming area during the summer of 2006 from three sampling designs. The first design sampled vegetative characteristics at 246 training sample plots across four QuickBird scenes for training model development. The second design targeted model validation of the Landsat 37/31 study area by using an independent sample of 71 randomly located plots (see fig. 3). The third design targeted model validation of the microstudy area by using an independent sample of 32 randomly located plots (see fig. 2). Field plots for training samples were collected on average within 24 days of the satellite overpass (table 2).

Model predictions-QuickBird imagery.-We generated predictions for all eight rangeland components across each of the four QuickBird scenes independently (fig. 6). One of those four scenes, site 3 , is detailed here. On the basis of crossvalidation correlation of training data to modeled output, $\mathrm{R}^{2}$ values ranged from a low of 0.75 for $A$. $t$. wyomingensis sagebrush to a high of 0.89 for bare ground (table 3). RMSE values ranged from 6.38 percent for bare ground to 2.99 percent for sagebrush. On the basis of these RMSE results, our bare ground prediction of 20 percent from the model would typically range from 13.42 percent to 26.38 percent in measured results on the ground. Our sagebrush prediction of 20 percent from the model would typically range from 17.01 percent to 22.99 percent in measured results on the ground (table 3 ). Another measure of model robustness was determined by the summation of the four primary cover components (100 percent is the summation ideal). For site 3, 79 percent of the pixels summed within 5 percent of the 100-percent ideal, and 95 percent of the pixels summed within 10 percent of the 100 -percent ideal.

$$
\text { Model predictions - Landsat and AWiFS imagery.- }
$$

We generated independent predictions for each of the eight rangeland components across both the microstudy and Landsat 37/31 study areas by using both Landsat and AWiFS imagery

(fig. 5). Component prediction accuracy results presented here were determined by using validation samples independent from training samples. For Landsat imagery, $\mathrm{R}^{2}$ values on the microstudy area ranged from a low of 0.15 for herbaceousness to a high of 0.73 for bare ground. $\mathrm{R}^{2}$ values across the $37 / 31$ study area ranged from a low of 0.09 for $A$. $t$. wyomingensis sagebrush to a high of 0.67 for bare ground (table 3 ). However, the best indicator of accuracy for the typical user is the RMSE. These values report accuracy in the units of the prediction and, as an absolute measure, are less sensitive to the loss of dynamic range as the scale changes. For Landsat, RMSE values on the microstudy area ranged from 13.21 percent for bare ground to 6.53 percent for shrub. RMSE values across the $37 / 31$ study area ranged from 12.07 percent for bare ground to 6.34 percent for sagebrush. On the basis of these RMSE results at the full Landsat scene scale, a bare ground prediction of 20 percent from our model would typically range from 7.93 percent to 32.07 percent in measured results on the ground, and a sagebrush prediction of 20 percent from our model would typically range from 13.66 percent to 26.34 percent in measured results on the ground (table 3 ). Another measure of model robustness was determined by the summation of the four primary cover components (100 percent is the summation ideal). For the microstudy area, 77 percent of 


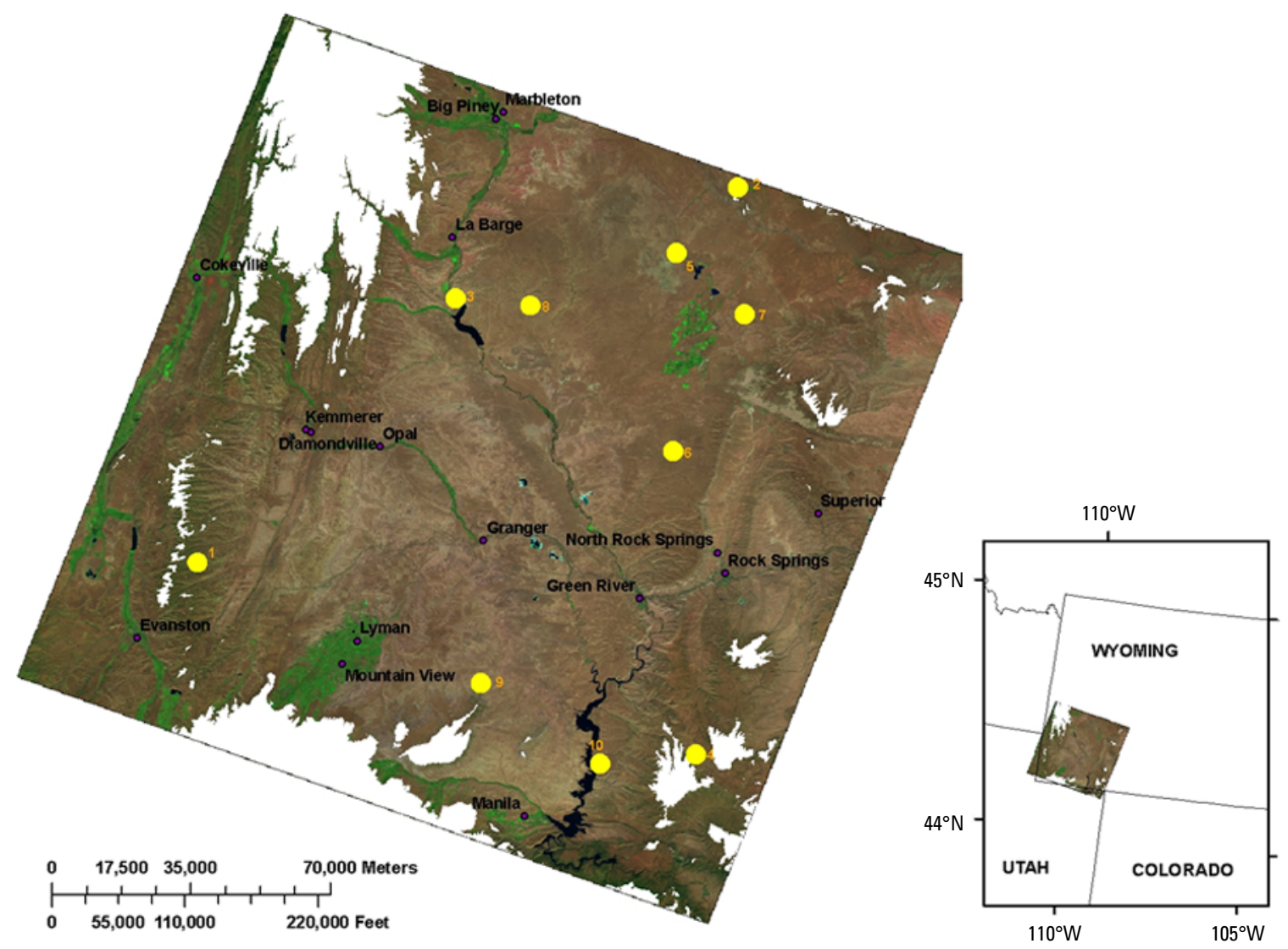

Figure 4. Location of 10 accuracy assessment focus areas (in yellow) across the Landsat 37/31 study area.

\section{4-m QuickBird}

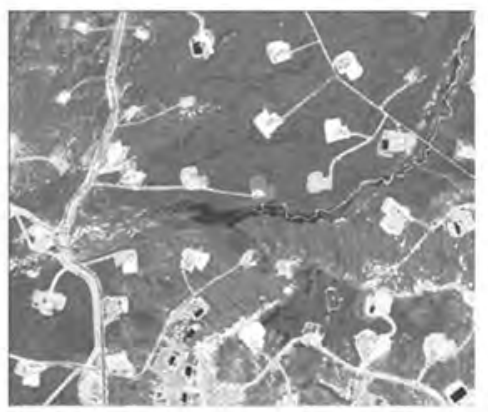

Explanation

Percent Bare Ground 30-m Landsat

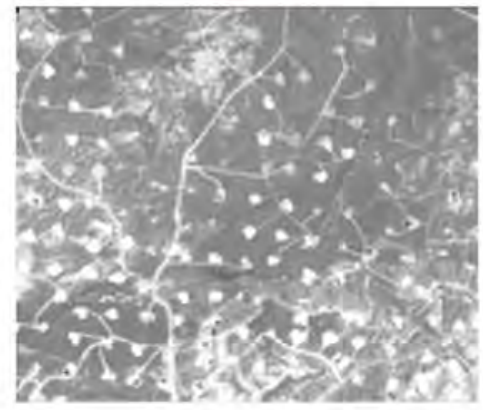

56-m AWiFS

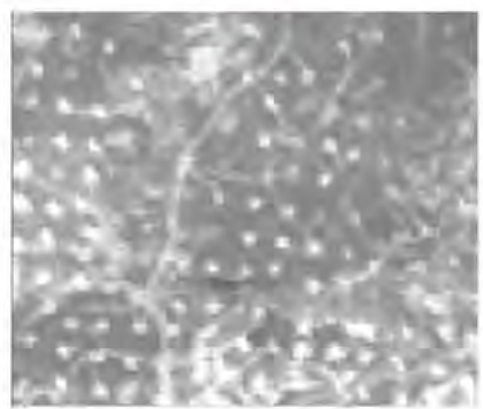

0 50 100

Figure 5. Example of percent bare ground predictions in QuickBird site 3 at three spatial scales. 
the Landsat pixels summed within 5 percent of the 100-percent summation ideal (between 95 and 105 percent), and 98 percent of the Landsat pixels summed within 10 percent of the 100-percent summation ideal (between 90 and 110 percent). For the full 37/31 study area, 55 percent of the Landsat pixels summed within 5 percent of the 100-percent summation ideal (between 95 and 105 percent), and 84 percent of the Landsat pixels summed within 10 percent of the 100-percent summation ideal (between 90 and 110 percent).

Accuracy results for the AWiFS component predictions were also determined by using validation samples independent from training samples and were typically not as robust as predictions from Landsat imagery. AWiFS $\mathrm{R}^{2}$ values on the microstudy area ranged from a low of 0.20 for herbaceousness to a high of 0.57 for litter. $\mathrm{R}^{2}$ values across the $37 / 31$ study area ranged from a low of 0.02 for A. t. wyomingensis sagebrush to a high of 0.50 for bare ground. AWiFS RMSE values on the microstudy area ranged from 18.53 percent for bare ground to 7.58 percent for sagebrush. RMSE values across the $37 / 31$ study area ranged from 14.11 percent for bare ground to 6.68 percent for sagebrush. On the basis of these RMSE results across the Landsat 37/31 study area, a bare ground prediction of 20 percent from our model would typically range from 5.89 percent to 34.11 percent in measured results on the ground, and a sagebrush prediction of 20 percent from our model would typically range from 13.32 percent to 26.68 percent in measured results on the ground (table 3 ). Another measure of model robustness was determined by the summation of the four primary cover components (100 percent is the summation ideal). For the microstudy, 9 percent of the AWiFS pixels summed within 5 percent of the 100-percent summation ideal, and 56 percent of the AWiFS pixels summed within 10 percent of the 100-percent summation ideal. For the full $37 / 31$ study area, 75 percent of the AWiFS pixels summed within 5 percent of the 100-percent summation ideal, and 96 percent of the AWiFS pixels summed within 10 percent of the 100-percent summation ideal.

Table 2. Relation of QuickBird acquisitions to field sampling dates.

\begin{tabular}{cc}
\hline Site & $\begin{array}{c}\text { Number of days between QuickBird } \\
\text { acquisition and field measurement }\end{array}$ \\
\hline QB site 1 & 42 \\
QB site 2 & 0 \\
QB site 3 & 24 \\
QB site 4 & 31 \\
\hline Average & 24 (standard error 7.46 +/- 7.33 days) \\
\hline
\end{tabular}

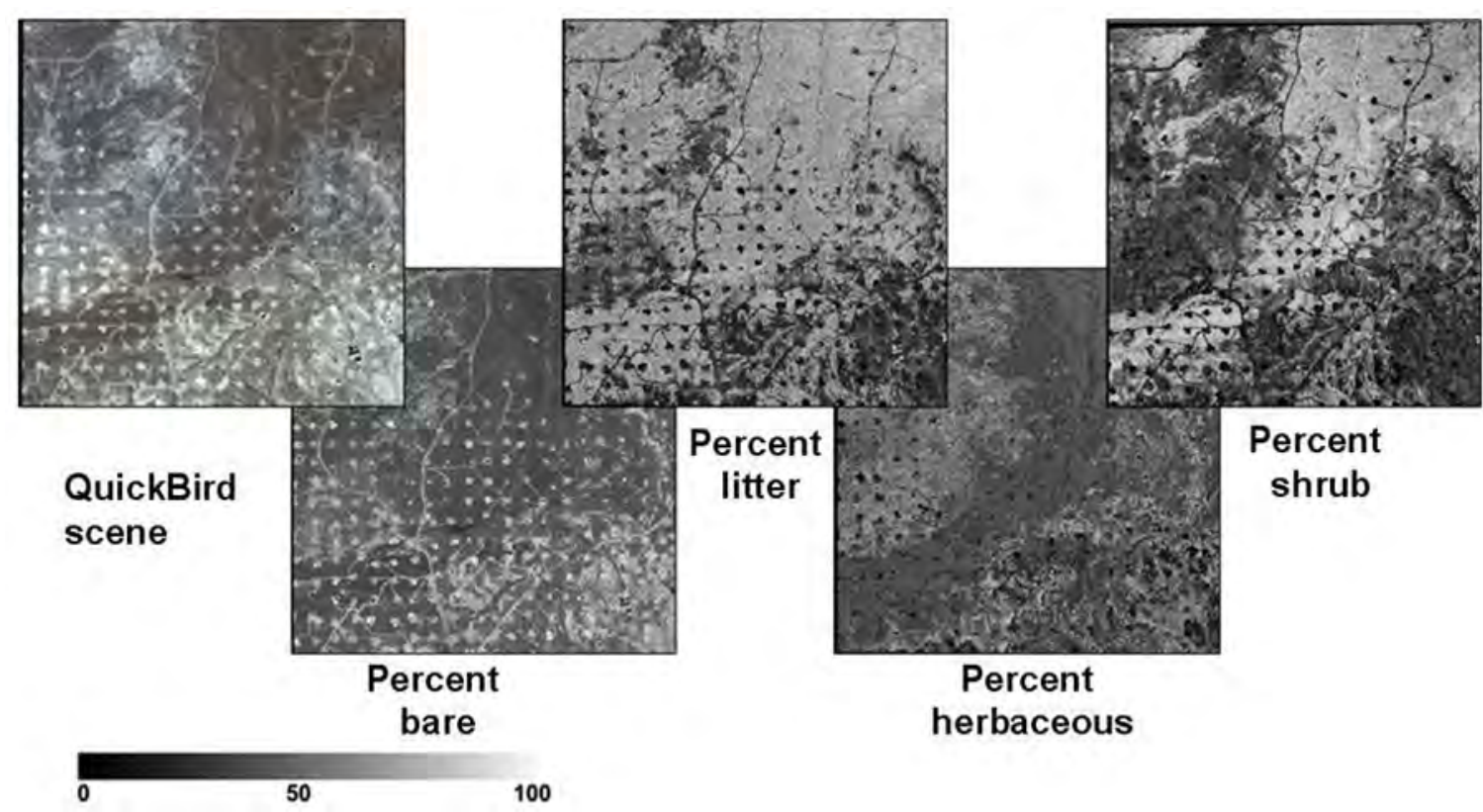

Figure 6. Examples of predictions for four primary components from QuickBird imagery in QuickBird site 3. 
Table 3. Accuracy assessment of all variable predictions for each study site and sensor.

[Root mean square error (RMSE) values are in the units of model prediction (percent or height). N, number; $\mathrm{R}^{2}$, coefficient of determination; RMSE, root mean square error; \%, percent; SE, standard error; AWiFS, Advanced Wide Field Sensor]

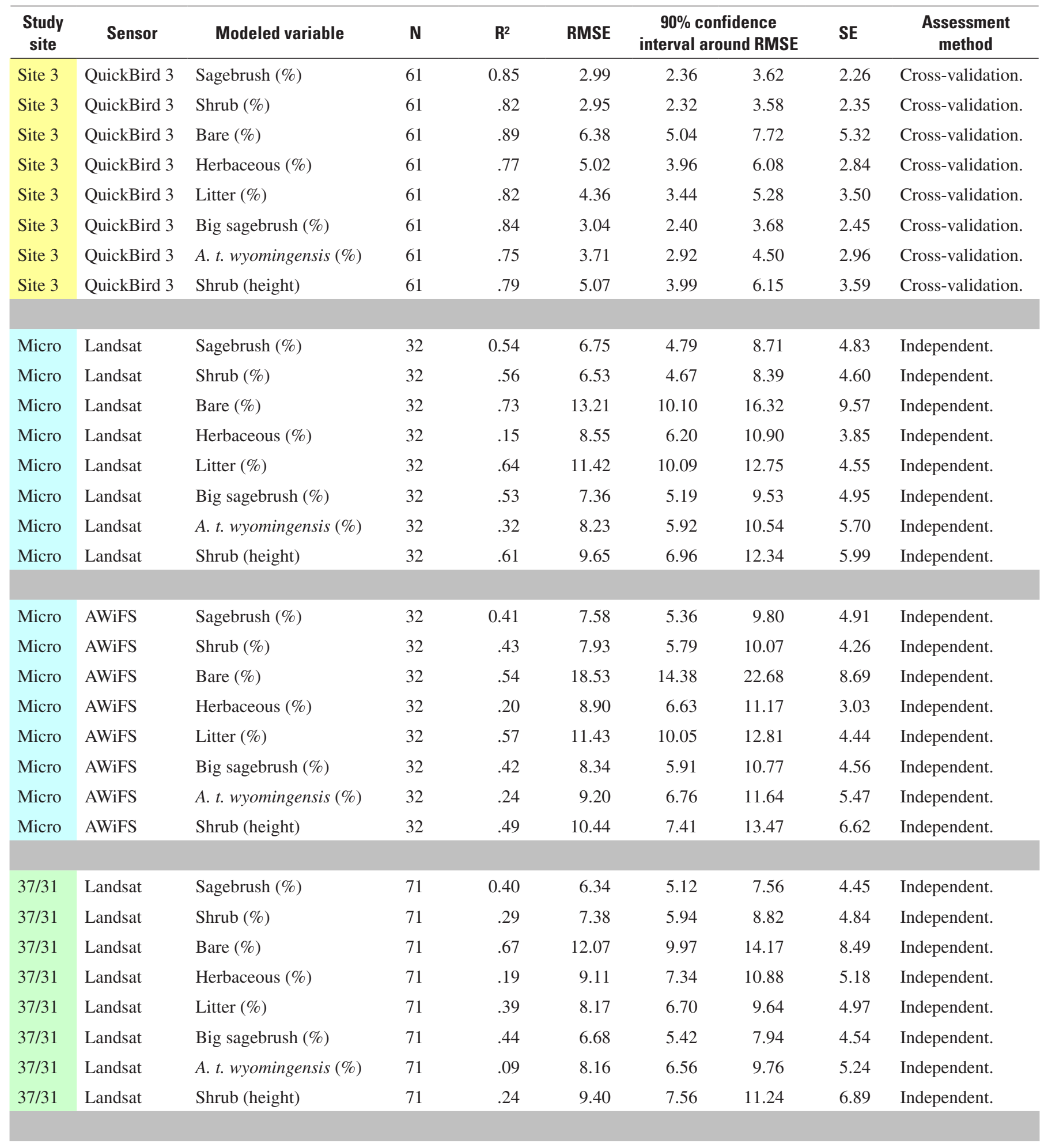


Table 3. Accuracy assessment of all variable predictions for each study site and sensor. — Continued

[Root mean square error (RMSE) values are in the units of model prediction (percent or height). N, number; $\mathrm{R}^{2}$, coefficient of determination; RMSE, root mean square error; \%, percent; SE, standard error; AWiFS, Advanced Wide Field Sensor]

\begin{tabular}{rllrrrrrrl}
\hline $\begin{array}{c}\text { Study } \\
\text { site }\end{array}$ & Sensor & Modeled variable & N & R & RMSE & $\begin{array}{c}\text { 90\% confidence } \\
\text { interval around RMSE }\end{array}$ & SE & $\begin{array}{c}\text { Assessment } \\
\text { method }\end{array}$ \\
\hline $37 / 31$ & AWiFS & Sagebrush (\%) & 71 & 0.36 & 6.68 & 5.43 & 7.93 & 4.49 & Independent. \\
$37 / 31$ & AWiFS & Shrub (\%) & 71 & .31 & 7.61 & 6.19 & 9.03 & 4.98 & Independent. \\
$37 / 31$ & AWiFS & Bare (\%) & 71 & .50 & 14.11 & 11.11 & 17.11 & 11.32 & Independent. \\
$37 / 31$ & AWiFS & Herbaceous (\%) & 71 & .15 & 10.55 & 8.66 & 12.44 & 6.30 & Independent. \\
$37 / 31$ & AWiFS & Litter (\%) & 71 & .27 & 8.64 & 7.02 & 10.26 & 5.28 & Independent. \\
$37 / 31$ & AWiFS & Big sagebrush (\%) & 71 & .36 & 7.70 & 6.33 & 9.07 & 4.98 & Independent. \\
$37 / 31$ & AWiFS & A.t. wyomingensis (\%) & 71 & .02 & 9.13 & 7.34 & 10.92 & 5.99 & Independent. \\
$37 / 31$ & AWiFS & Shrub (height) & 71 & .18 & 9.94 & 8.00 & 11.88 & 7.12 & Independent. \\
\hline
\end{tabular}

\section{Discussion}

This work potentially offers the most rigorous attempt to date for large-area remote sensing quantification of sagebrush systems. Initial results from the first phase of this research are encouraging, and are discussed here in relation to project specific objectives.

Field sampling.-The field sampling protocol strived to achieve a reasonable balance among scale, effort, access, and precision across all components. The sample site selection protocol using QB segmentation was especially effective for optimizing field collection to maximize spectral utility, and it facilitated successful application to larger imagery scales. We also feel the average time ( 24 days) between the collection of the image and field sampling was reasonable, given the difficult logistical issues involved, and dramatically reduced the likelihood of confounding phenologic issues in our sampling. The 1-m Daubenmire frame used as a vehicle for canopy measurement represented a compromise strategy to adequately measure all components. Initial field trials of other methods (2-m Daubenmire frame, line intercept method) showed some tendencies for the 1-m frame to underrepresent shrub canopies by $1-3$ percent. However, the utility of the $1-\mathrm{m}$ frame for more accurate herbaceous and litter estimates compensated for the shrub issues, and overall, it offered a reasonable compromise for the adequate measurement of all components.

Model prediction-QuickBird imagery.-On the basis of the modeled results at the QuickBird (2.4-m) scale, our stratification and field sampling approaches successfully measured the range of variability of rangeland components. The multispectral QuickBird imagery also performed well as an extrapolation medium for the field sampling. The $2.4-\mathrm{m}$ pixel scale allowed the RT enough spatial area for subpixel estimates to be relevant, while maintaining high resolution. Component predictions at this 2.4-m scale were within 3-6 percent of the prediction; the mean RMSE across all predictions was 4.19 percent. We feel results with these thresholds represent a successful modeling strategy robust enough to support further spatial extrapolation at coarser scales and provide a solid foundation for monitoring.

Model prediction - Landsat and AWiFS imagery.-While model outputs and accuracies at the QuickBird resolution across the State of Wyoming would be ideal, the current difficulty and cost of imagery acquisition, field sampling, and processing at this scale are prohibitive. Coarser scale imagery such as Landsat and AWiFS, however, offer ideal mediums to further extrapolate our component models from the QuickBird scales to larger landscapes. The designation of the microstudy area allowed us to locally test the potential of Landsat and AWiFS imagery predictions to scale up from QuickBird. Predictions were extrapolated from a single QuickBird image to within the microstudy area. As expected, moving to a coarser resolution pixel (even with a significant increase in the number of input variables for Cubist to use) decreased our prediction confidence. The mean RMSE (from crossvalidation) across all eight components was 4.19 percent for the QuickBird scale, but when Landsat and AWiFS predictions were extrapolated to the microstudy site, the mean RMSE (from independent validation) increased to 8.96 percent for Landsat and 10.29 percent for AWiFS.

One reason for this loss of precision is simply a function of spatial scale and is described as the Modifiable Areal Unit Problem (MAUP), where the mean value does not change but variance declines with increasing aggregation. Thus, the modeled range of a given variable becomes compressed as the spatial size of the pixel increases. Because ecological features such as shrubs have small canopies with wide spacing between individuals, the dynamic range of cover estimates for 2.4-m pixels can range from 0 to 100 percent, whereas the dynamic range at 30-m cell size only varies from 0 to 45 percent. Hence, the dynamic range of the data is compressed simply by scale of representation and further compounded by the resistance of regression trees to adequately model outliers (effectively further reducing the dynamic range of the predicted 
models). While our methodological approach of weighting three bins of training data (low, medium, and high ranges) across three bags to help Cubist address the full dynamic range of the predictions helped to overcome some of the MAUP, the MAUP cannot be entirely overcome as scales change. Component predictions will tend to be most accurate in the middle ranges, and accuracies in predicting high and low cover will be reduced at the tails of the distribution. A scatterplot of predicted versus observed sagebrush canopy cover (Artemisia spp.) for the $37 / 31$ study area displays this effect (fig. 7).

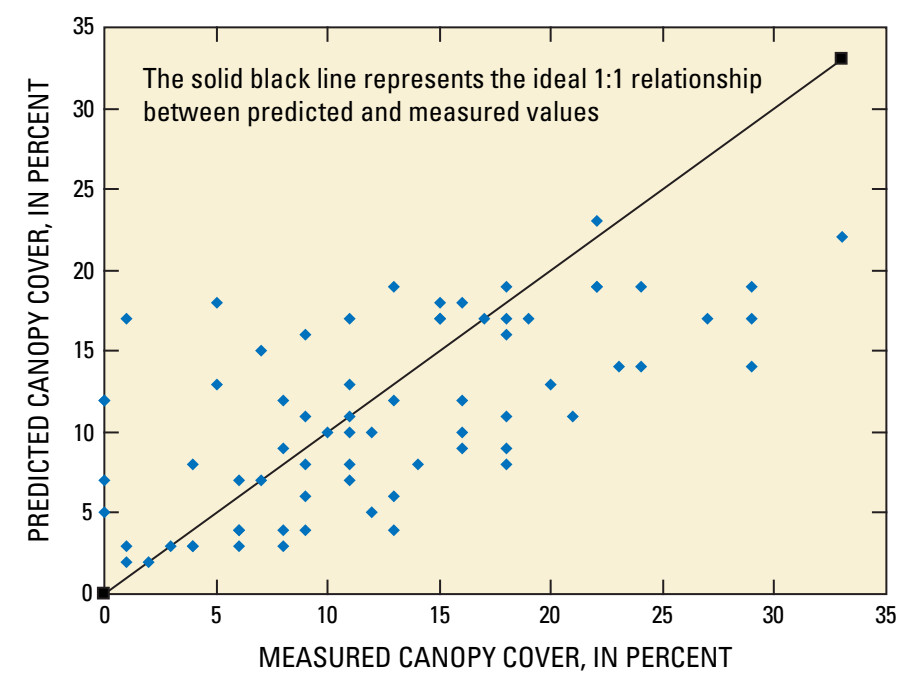

Figure 7. Predicted versus measured sagebrush canopy cover (Artemisia spp.) from Landsat imagery for the Landsat 37/31 study area.

At the full 37/31 study area, all Landsat and AWiFS predictions provided a mean RMSE of 8.41 percent for Landsat and 9.30 percent for AWiFS. The slightly improved RMSE results for some of the components across the full Landsat scene versus the microstudy area were a little surprising, given our expectation that focusing on the microstudy area would optimize model predictions. We have considered at least three potential factors that could have affected these results. First, the time gap between the collection of training and validation plots in the microstudy area was much greater than elsewhere (45 days), which potentially was manifested in measured plot differences due to the phenological trajectory of the vegetation (note the Landsat litter RMSE differences in table 3). Second, the microstudy area did not exhibit the full ecological dynamic range of most components, which were exhibited across the full Landsat 37/31 study area, leading to potentially more dynamic range compression in the predictions for this area. Third, the microstudy area had an abundance of training data relative to its size that were not available for the full 37/31 study area. Although multiple training data sampling trials were completed in the microstudy area to optimize predictions, overfitting of the RT models could still have occurred. This would result in a model that predicts very well over the spatial extent of the training (the QuickBird footprint) but less well in areas to which it needs to extrapolate.

Upon full extrapolation of the Landsat and AWiFS predictions to the $37 / 31$ study area, model performance is constrained by a combination of limitations among spectral discrimination, terrain differences, and training data profiles. Numerous trials were conducted to fully explore the discrimination potential of various spectral combinations, band ratios, and modeling scenarios. Perhaps the greatest area for model improvement lies in developing more optimal training profiles. To understand contributions of additional QuickBird sites to model accuracy, we assessed the stability of predictions for the $37 / 31$ study area on the basis of three components and various QuickBird training site combinations. Model results from these combinations were analyzed by using the 71 accuracy assessment plots. The results for the sagebrush canopy component are presented in figure 8. All three tested components (sagebrush, bare ground, and herbaceousness) indicated improving model accuracy with the addition of the fourth QuickBird site. We hypothesize that additional QuickBird training sites would further improve accuracy. Hence, the next phases of this research will include increases in training site data to measure additional improvement in model performance.

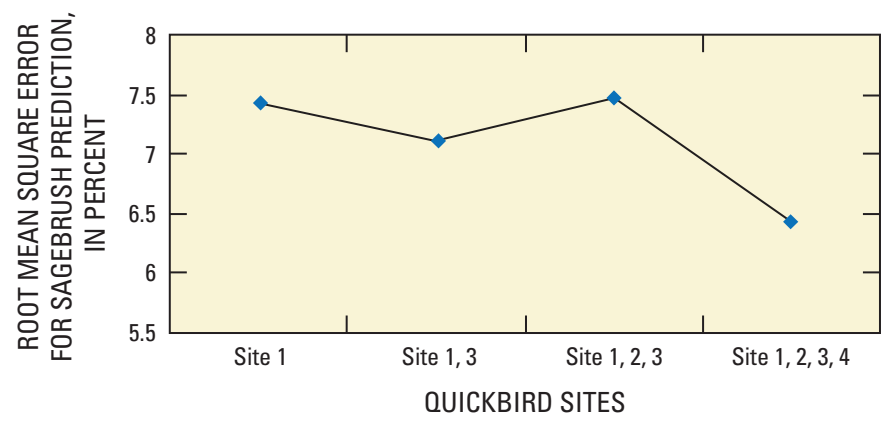

Figure 8. Landsat sagebrush prediction accuracy, by QuickBird training site combinations.

This research reveals that significant incremental methodological improvements can be made in rangeland habitat classification from remote sensing. However, the fundamental challenge of deriving estimates of rangeland components with high precision and accuracy in a bright spectral environment with large proportions of bare soil remains significant. Within this context, we believe these results offer significant improvement in rangeland quantification at multiple scales and offer users products that have been rigorously validated. Our approach of using presampling segmentation and landscape stratification, detailed ground sampling, and regression tree modeling of rangeland components resulted in reliable component predictions that we feel offer sufficient RMSE accuracies to provide baseline products for a variety of potential applica- 
tions. Further, these methods have been specifically developed to be both operational and cost effective over large areas to enable their potential application across entire ecosystems. Finally, because these modeled components are designed to provide maximum flexibility to users at various scales, they can potentially be used to assess specific habitat requirements, assess wildlife habitat relations over large landscapes for multiple species, provide a rangeland monitoring database that discriminates significant change over time, and provide other ecosystem assessments.

\section{Future Work}

While the first phase of this research is reported here, additional phases are now in progress that will broaden the scope to include new components and larger areas, strive to increase component accuracies, track change over time, and ultimately model wildlife population trends against these changes. Planned products include predictions for all eight rangeland components including 56-m AWiFS predictions for the entire State of Wyoming, 30-m Landsat predictions covering 75 percent of the State, new 2.4-m QuickBird imagery and field sampling in 2007 to bolster component accuracy, and testing of component change over time from 1984 to present at 30-m scales. Specifically, the second phase will develop similar QuickBird and Landsat predictions for Landsat path rows 36/30 and 35/29, encompassing a total of 13 QuickBird footprints in a broad diagonal transect through Wyoming with an additional 780 sampled polygons.

Once these predictions have been created, they will be applied to an AWiFS image to create a statewide prediction for 2006. The third phase of this research will incorporate an additional 18 QuickBird footprints that were sampled during the summer of 2007 (fig. 9). These additional footprints will both increase the existing sample of QuickBird training in current Landsat/AWiFS footprints to improve model accuracy and enable specific 2007 modeling in five new Wyoming Landsat footprints. These new samples will also enable testing of model accuracy and performance against various scenarios of training data (abundance, single-year, multiple-year) to develop an optimal operational model for generation of similar data in the future across the ecosystem. The fourth phase of this research will take the 2006/2007 components as an inventory baseline and subsequently develop historical classification by component from eras 1989 and 1982 to quantify component change over time. The fifth and final phase will include rigorous time-series change analyses and modeling wildlife population trends against changes in density of oil and gas activities and road developments. These analyses would be based on the use of existing and currently being developed

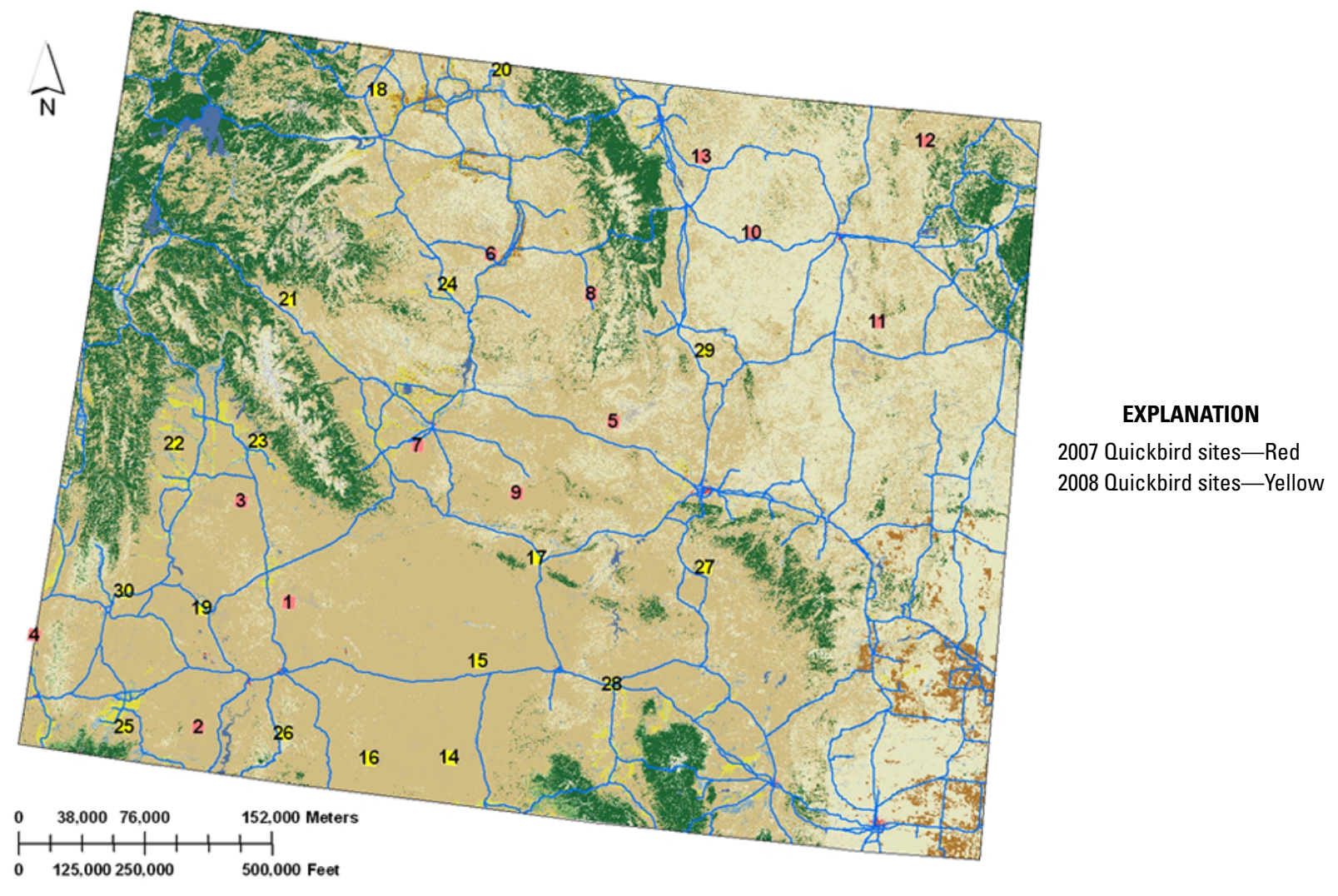

Figure 9. The location of 2006 and 2007 QuickBird samples over the 2001 National Land Cover Database. 
anthropogenic data layers (Aldridge, C.L., Fancher, T., Waltermire, R., Germaine, S., Nielsen, S.E., Baer, L., and Bauer, M., unpub. data, 2007) and existing wildlife datasets (such as sagegrouse lek data and Breeding Bird Survey data).

\section{Acknowledgments}

We thank S. Rehme, T. Perfors, and C. Mahony for their tireless work collecting field data. The Wyoming State office and the Lander Bureau of Land Management field office were instrumental in also supporting this project logistically. We also thank R. McKinley for his initial help with early research. Specifically, we thank T. Rinkes, R. Vigil, K. Henke, and D. Simpson for their support and interest in this research. We also thank the USGS Central Region office and all individuals involved with the Central Region Integrated Science Proposals for supporting this research. D.J. Saher, D. Neubaum, J. Vogelmann, and B. Wylie provided useful comments on earlier drafts of this report.

\section{References}

Aldridge, C.L., and Boyce, M.S., 2007, Linking occurrence and fitness to persistence- - a habitat-based approach for Greater Sage-Grouse: Ecological Applications, v. 17, p. 508-526.

Connelly, J.W., Knick, S.T., Schroeder, M.A., and Stiver, S.J., 2004, Conservation assessment of greater sage-grouse and sagebrush habitats: Cheyenne, Wyo., Western Association of Fish and Wildlife Agencies, 610 p.

Homer, C., Dewitz, J., Fry, J., Coan, M., Hossain, N., Larson, C., Herold, N., McKerrow, A., VanDriel, J.N., and Wickham, J., 2007, Completion of the 2001 National Land Cover Database for the conterminous United States: Photogrammetric Engineering and Remote Sensing, v. 73, no. 4, p. 337-341.

Homer, C., Huang, C., Yang, L., Wylie, B., and Coan, M., 2004, Development of a 2001 National Landcover Database for the United States: Photogrammetric Engineering and Remote Sensing, v. 70, no. 7, p. 829-840.

Quinlan, J.R., 1993, C4.5 programs for machine learning: San Mateo, Calif., Morgan Kaufmann Publishers, 302 p.

Schroeder, M.A., Aldridge, C.L., Apa, A.D., Bohne, J.R., Braun, C.E., Bunnell, D., Connelly, J.W., Deibert, P., Gardner, S.C., Hilliard, M.A., McAdam, S.M., Kobriger, G.D., McCarthy, C.W., McCarthy, J.J., Mitchell, D.L., Rickerson, E.V., and Stiver, S.J., 2004, Distribution of sage-grouse in North America: Condor, v. 106, p. 363-376. 
Publishing support provided by:

Helena Publishing Service Center

For more information concerning this publication, contact:

U.S. Geological Survey Earth Resources Observation and Science (EROS) Center

Sioux Falls, South Dakota

(605) 594-6151

Or visit the EROS Center Web site at:

World Wide Web: http://eros.usgs.gov/ 
